\title{
Repurposing current therapeutic regimens against SARS-CoV-2 (Review)
}

\author{
SOFIA K. KONSTANTINIDOU ${ }^{1,3 *}$ and IOANNIS P. PAPANASTASIOU ${ }^{2 *}$ \\ ${ }^{1}$ Oncology Unit, The Third Department of Medicine, Medical School, National and Kapodistrian University of Athens, \\ 11527 Athens; ${ }^{2}$ Division of Pharmaceutical Chemistry, Department of Pharmacy, School of Health Sciences, \\ National and Kapodistrian University of Athens, 15784 Athens, Greece
}

Received May 15, 2020; Accepted June 2, 2020

DOI: $10.3892 /$ etm.2020.8905

\begin{abstract}
The recent coronavirus outbreak has spread worldwide, with the exception of Antarctica, causing serious social and economic disruption. All disciplines of the science community are driven to confront the impact of the COVID-19 pandemic, as currently, there is neither prophylactic nor therapeutic treatments available. Due to the urgency of the situation, various research strategies are ongoing, in order to evaluate the therapeutic efficacy of repurposed and experimental drugs. The present review presents the most promising repurposed regimens, which may be used for the treatment of COVID-19. The drugs/bioactive substances presented herein belong to diverse therapeutic classes, including antimalarial, cardioprotective, angiotensin-converting enzyme 2 inhibitors, antiviral, anti-inflammatory and antiparasitic drugs. Therapeutic perspectives of vaccination and passive immunization are also reviewed.
\end{abstract}

\section{Contents}

1. Introduction

2. Currently available drugs against SARS-CoV-2

3. Miscellaneous

4. Immunization

5. Conclusions

Correspondence to: Miss Sofia K. Konstantinidou, Oncology Unit, The Third Department of Medicine, Medical School, National and Kapodistrian University of Athens, 152 Mesogion, 11527 Athens, Greece

E-mail: sissykonstantinidou@gmail.com

Present address: ${ }^{3}$ Clinical Pharmacy Department, Athens Medical Center, 5-7 Distomou Street, Marousi, 15125 Athens, Greece

* Contributed equally

Key words: SARS-CoV-2, COVID-19, pandemic, mechanism of action, clinical trials, vaccines

\section{Introduction}

The outbreak of the 2019 novel coronavirus in Wuhan, China, spread worldwide, becoming a pandemic in the beginning of 2020 (1). The World Health Organization (WHO) announced the name of the disease to be coronavirus disease-19 (COVID-19), and the Coronaviridae Study Group of the International Committee on Taxonomy of Viruses classified its etiological agent as severe acute respiratory syndrome coronavirus 2 (SARS-CoV-2) (Fig. 1) (2). This respiratory pathogen belongs to the viral family Coronaviridae, which was first identified in the mid-1960s $(3,4)$. Mutation and adaptation have driven the co-evolution of coronaviruses and their hosts, including humans, for thousands of years (5). Recently, in 2002-2003, the outbreak of severe acute respiratory syndrome coronavirus (SARS-CoV) increased the awareness of the fatal risk and medical importance of virulent coronavirus strains (6). In 2012, a novel zoonotic coronavirus related to SARS was identified in the Middle East, known as Middle East respiratory syndrome coronavirus (MERS-CoV), which had a mortality rate of $36 \%$ (7). Phylogenetic analysis revealed that SARS-CoV-2 is quite distant from SARS-CoV ( 79\%) and MERS-CoV ( 50\%) (8). Compared with the latter two strains, SARS-CoV-2 has a lower case-fatality rate; however, it spreads more efficiently (9). In response to the emergence of the pandemic, a third of the global population was set on lockdown, and the authorities implemented measures to slow the spread of the infection, from mandatory geographic quarantines to non-mandatory recommendations. At present, as there is neither prophylactic nor therapeutic treatment for COVID-19, the world has accelerated research on treatments and vaccines for this threat (10). Due to the urgency of the situation, a number of already approved and marketed drugs are being tested for repurposing, conforming to a recent strategic innovation in medicinal chemistry and drug discovery (11).

\section{Currently available drugs against SARS-CoV-2}

Antimalarial regimen: Chloroquine and hydroxychloroquine (Fig. 2). Chloroquine and its derivative hydroxychloroquine have previously been used as clinical treatments in various diseases (12-14). Chloroquine hydrochloride and phosphate, and its derivative, hydroxychloroquine sulfate, have been 
commercialized for the prophylaxis and treatment of malaria, chronic Q-fever and autoimmune diseases (15). Both chloroquine and hydroxychloroquine are available as racemates, which may exhibit stereoselective metabolism and efficacy (16). Chloroquine is a 4-aminoquinoline analogue that acts effectively as a schizonticidal drug against the erythrocytic forms of all types of plasmodia (17). It has also been reported to have modest results against chronic hepatitis $C$ (12). Numerous mechanisms of action have been suggested to clarify the activity and the side effects of chloroquine and hydroxychloroquine, most of them implicating lysosomal activity on a molecular level (18), autophagy and signaling pathways (19), and/or immunomodulatory potency, by reducing anti-inflammatory cytokines (20). This observation might lead to a new perspective and the therapeutic consideration of lysosomotropic agents and/or sigma receptor(s)-related drugs for the treatment of COVID-19 $(21,22)$.

In vitro studies have revealed that chloroquine is highly effective against SARS-CoV-2. In an in vitro study by Keyaerts et al (23), it was shown that chloroquine exhibited antiviral activity with an IC50 of $8.8 \mathrm{M}$. Wang et al (24) also reported that the $90 \%$ maximal effective concentration value of chloroquine against SARS-CoV-2 in Vero E6 cells was $6.90 \mu \mathrm{M}$, thus being potentially clinically applicable. In addition, hydroxychloroquine was tested in vitro by Liu et al (25), where it was found to efficiently inhibit SARS-CoV-2 by blocking the entry step of the virus, as well as its post-entry stages. Until new medications are approved, chloroquine phosphate or its derivative, hydroxychloroquine, in combination with azithromycin and/or antimicrobial therapy, are being adjuvantly used for patients with COVID-19 in various countries, such as France, Greece, China and USA $(26,27)$. The first results on humans were obtained from Chinese hospitals, which revealed the superiority of chloroquine compared with the control group, as it reduced the exacerbation of pneumonia, duration of symptoms and delayed viral clearance $(27,28)$. Therefore, China recommended chloroquine for the treatment and prevention of COVID-19 (14). Patients with COVID-19 pneumonia may benefit from the anti-viral and anti-inflammatory action of chloroquine (29).

As well as treating malaria, chloroquine and hydroxychloroquine have been used in the past against various rheumatic diseases, including systemic lupus erythematosus and rheumatoid arthritis. Both drugs exhibit their antiviral action in a short time after their administration and cause immune modification, as they reduce the production of cytokines (14). With regards to the reduced production of proinflammatory cytokines, these drugs mainly affect IL-1 and IL-6, and inhibit the activation of Toll-like receptors (TLRs) (30).

An investigation led by Professor Didier Raoult recently released the results of a new hydroxychloroquine treatment study on 1,061 patients in Marseille, France (26). In this cohort study, the patients were administered a hydroxychloroquine-azithromycin (HCQ-AZ) combination, for $\geq 3$ days, and then were followed-up for $\geq 9$ days. HCQ-AZ led to a good clinical outcome within 10 days of treatment $(91.7 \%)$ and mortality was lower in patients who had received the HCQ-AZ combination for $>3$ days. This study revealed that HCQ-AZ in the early phases of mild COVID-19 could prevent exacerbation of the infection; however, it still remains a question if it has any effects on severe cases (26).
The optimal dosages of chloroquine and hydroxychloroquine, as well as the required duration of administration for the treatment of COVID-19, have not been determined, and several clinical studies have used different dosing regimens (31-33). The ongoing PATCH Trial (34) (randomized study with 400 participants) aims to compare different dosage forms of hydroxychloroquine in terms of their effectiveness against COVID-19. However, for patients with renal or hepatic impairment, there are no specific dosage recommendations, except for the advice 'use with caution'. Treatment with chloroquine can lead to severe adverse effects and overdosing can lead to pulmonary edema and circulatory collapse, which are even more severe in the elderly, thus dose reduction is recommended (35).

Particular care is required in the use of chloroquine phosphate, hydroxychloroquine and azithromycin, due to their cardiotoxicity and QT prolongation (35). A multinational cohort study conducted by Lane et al (36) indicated that when azithromycin was added to hydroxychloroquine, patients exhibited increased risk of 30-day cardiovascular mortality, chest pain and heart failure. Therefore, due to the potentially synergistic effects of HCQ-AZ on QT length, caution should be taken. Patients with chronic diseases, including kidney failure, liver disease, epilepsy and myasthenia gravis, or patients on medications that include active substances incompatible with these drugs, will require strict monitoring because they are likely to cause serious arrhythmias. Other risk factors that can cause arrhythmias (e.g. torsades de pointes) include hypomagnesaemia, hypokalemia, bradycardia, heart failure, advanced age and QT $>450-500 \mathrm{msec}$. In addition, chronic treatment or high doses of chloroquine and hydroxychloroquine may lead to damage to the retina. It is also important that checks for lack of the G6PD enzyme are conducted, as lack of this enzyme is associated with the toxicity of these drugs, mainly leading to retinopathy (37).

Recently, a multinational worldwide study conducted on patients hospitalized with COVID-19 revealed that the use of hydroxychloroquine or chloroquine (in combination with or without a macrolide) was associated with no evidence of benefit, but instead was associated with an increased risk of ventricular arrhythmias and a greater hazard for in-hospital mortality (38). However, the article was retracted as several concerns were raised with regards to the validity of the patients' data. Currently, there is no effective and safe chloroquine dosage treatments for COVID-19. Karalis et al (39) used simulation techniques for optimization of dosage regimens and suggested specific recommendations to healthcare specialists.

Targeting cardioprotective derivatives: Colchicine. COVID-19 has various cardiovascular implications, in particular : i) Patients with COVID-19 and pre-existing cardiovascular disease exhibit a high risk of severe disease and death; ii) COVID-19 has multiple direct and indirect cardiovascular complications; and iii) currently used therapies against COVID-19 may have cardiovascular side effects. For all these reasons, colchicine has been proposed to be added to the therapeutic regimen against SARS-CoV-2 (40). This drug has been used for several years against diseases such as gout, Mediterranean fever and pericarditis, and in addition to its other properties, it has exhibited anti-inflammatory action (41). COLCORONA (42) is a multi-center, randomized, double-blind trial with 6,000 participants that is currently in progress, which 


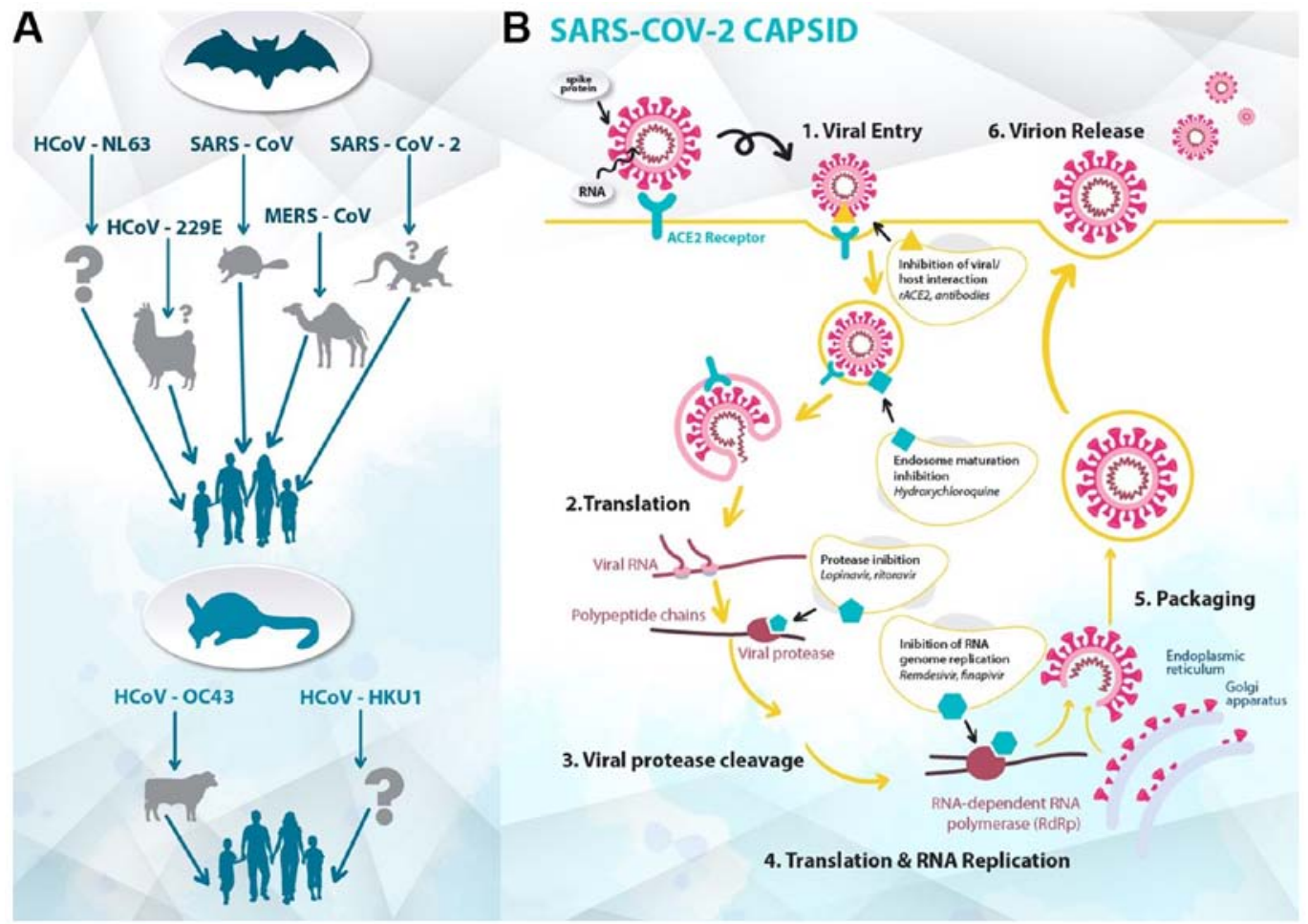

Figure 1. (A) Animal hosts of coronaviruses. Arrows depict the transmission of different coronavirus strains from their natural hosts (bats or rodents), through the intermediate hosts (camelids, civets, dromedary camels, pangolins or bovines), to humans. (B) Stages and targets of the life cycle of SARS-CoV-2 in host cells. SARS-CoV-2, severe acute respiratory syndrome coronavirus 2; HCoV, human coronavirus; MERS, Middle East respiratory syndrome; ACE2, angiotensin-converting enzyme 2 .<smiles>CCN(CC)CCC[C@H](C)Nc1ccnc2cc(Cl)ccc12</smiles>

Chloroquine<smiles>CCN(CCO)CCC[C@H](C)Nc1ccnc2cc(Cl)ccc12</smiles>

Hydroxychloroquine

Figure 2. Structures of chloroquine and hydroxychloroquine.

aims to investigate whether short-term treatment with colchicine may reduce mortality and lung complications in patients with COVID-19. Moreover, GRECCO-19 (41) is a smaller randomized clinical trial, with an estimated 180 participants, which was launched in Greece with the aim of identifying the role of colchicine in patients with COVID-19 and determining whether it has an effect on the clinical course of COVID-19 by reducing myocardial necrosis and pneumonia (41).

Targeting angiotensin-converting enzyme 2 (ACE2) (Fig. 3). The entry of SARS-CoV-2 into cells is associated with the binding of the viral spike $S$ protein with ACE2 (43). A defined receptor-binding domain in the aforementioned spike protein specifically recognizes its host receptor on ACE2. Both coronavirus strains, SARS-CoV and SARS-CoV-2, share a high sequence identity in spike S protein $(\sim 76 \%)(44)$. This similarity of receptor recognition may be a major factor associated with host range and cross-species mutations, and with the emergence of coronavirus infections (45). ACE2 is a zinc metalloproteinase and is part of the renin-angiotensin system (RAS), which maintains cardiovascular homeostasis and regulates blood pressure through electrolyte balance (46). ACE2 hydrolyzes the carboxy-terminal leucine from angiotensin I (decapeptide) to produce the nonapeptide angiotensin-(1-9). ACE2 also converts angiotensin II (octapeptide) to angiotensin-(1-7), which induces blood vessel relaxation, and anti-proliferative and anti-oxidative stress activities. Regarding coronavirus infections, ACE2 mediates S protein-driven host cell entry $(47,48)$. Moreover, the viral spike $S$ protein has been suggested to downregulate ACE2 expression in host cells, thus leading to severe lung injury and acute lung failure (49). The formation of the S protein-ACE2 complex has also been reported to lead to a partial decrease or total loss of the enzymatic ACE2 function in these cells, thus increasing the tissue concentration of proinflammatory angiotensin II. This is affected by decreasing its degradation 


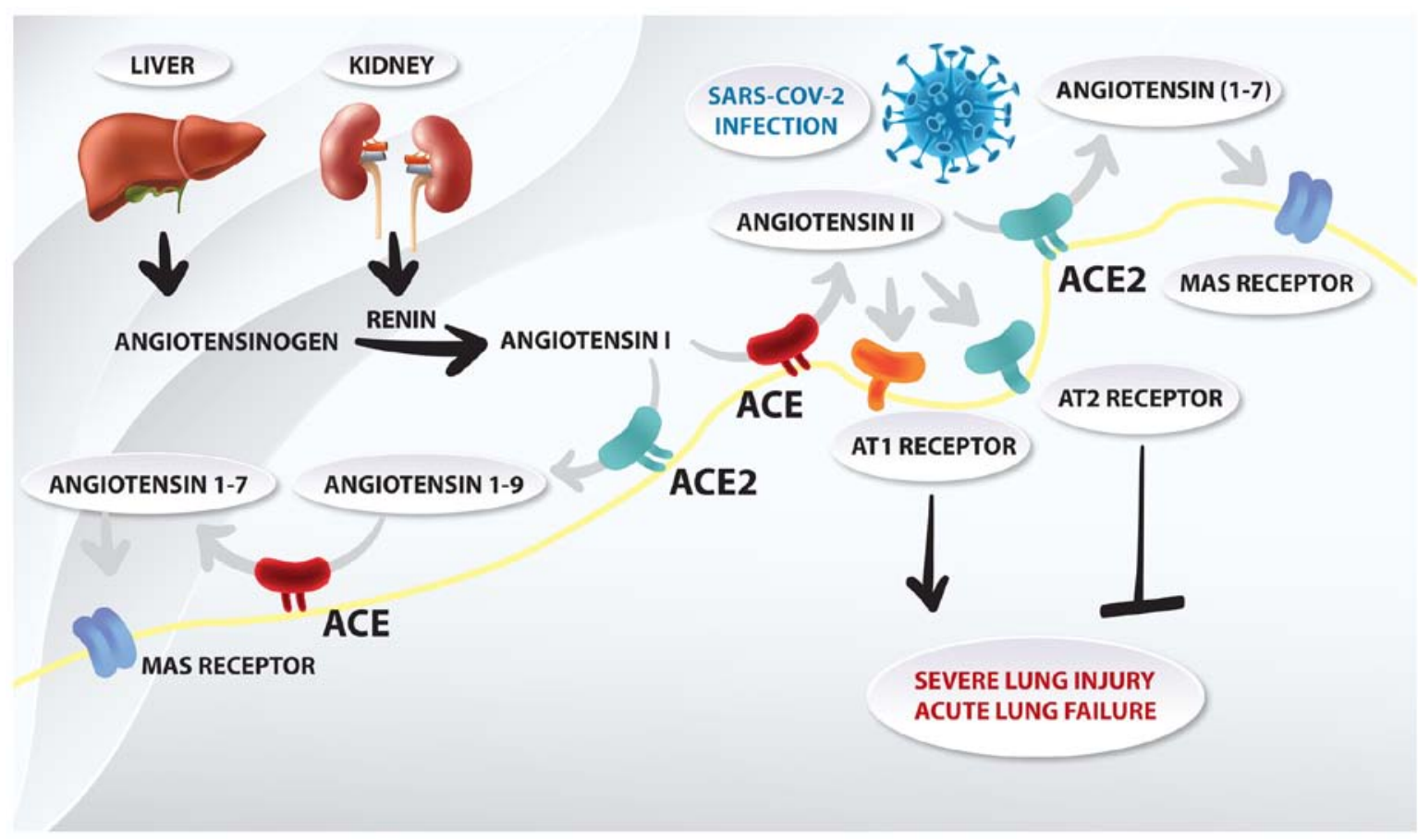

Figure 3. Schematic representation of the role of the renin-angiotensin system in acute lung failure of coronavirus disease 19. SARS-CoV-2, severe acute respiratory syndrome coronavirus 2; ACE2, angiotensin-converting enzyme; AT, angiotensin II receptor.

and reducing the concentration of angiotensin-(1-7), which is its physiological antagonist. High levels of angiotensin II in the lung interstitium can promote apoptosis, thus initiating an inflammatory process and resulting in the release of proinflammatory cytokines, which may eventually lead to acute respiratory distress syndrome (ARDS) (50).

The therapeutic approaches (51) against ACE2-mediated COVID-19 may involve: i) Vaccine production based on the spike $\mathrm{S}$ protein (52), ii) inhibition of virus and host cell fusion via transmembrane protease serine 2 (TMPRSS2) $(53,54)$ and iii) blocking ACE2 receptor $(55,56)$.

Another valuable regulating factor of the RAS with regards to COVID-19 are angiotensin II receptor blockers (ARBs), previously described as angiotensin II type 1 (AT1) receptor antagonists. Initially, it was hypothesized that patients treated with ARBs or ACE inhibitors would be at a higher risk of new coronavirus infection $(57,58)$. This is due to the fact that expression of ACE2, which is the enzyme that SARS-CoV-2 binds to, is increased in patients treated with ARBs or ACE inhibitors (57). ARBs directly protect the endothelial barrier integrity of the lungs and indirectly upregulate ACE2, reducing inflammation, organ fibrosis and endothelial injury (56). Among these blockers, losartan has been suggested to be a drug candidate as it can strongly bind to AT1 (59). Notably, Zhang et al (60) revealed that hospitalized patients with COVID-19 and hypertension, when treated with ACE inhibitors or ARBs, exhibited a lower risk of all-cause mortality compared with non-users. According to Rothlin et al (50), out of all of the ARBs available, telmisartan may have best pharmacological properties to be evaluated for COVID-19.

It has also been reported that statins upregulate ACE2 via epigenetic modifications and interfere with its signaling. Castiglione et al (61) hypothesized that adjuvant treatment or continuation of already existing statin therapy could improve the clinical course of patients with COVID-19. This finding may be due to their immunomodulatory action or by the prevention of cardiovascular damage (62). Alongside their lipid-lowering activity, statins may reduce inflammation and oxidative stress, thus contributing to their beneficial action on cardiovascular diseases. In addition, statins intervene in the immune response at different levels, including immune cell adhesion and migration, and cytokine production (61). Statins also restore the vascular redox balance by reducing reactive oxygen species, and ameliorating nitric oxide bioavailability, endothelial function and integrity (61). Statins, alongside ARBs, have been reported to be effective in targeting the host response and preventing endothelial barrier damage in patients infected with the Ebola virus during the recent Ebola outbreak in West Africa (63). These findings propose a research direction against the SARS-CoV-2 virus (64).

\section{Targeting antivirals}

Remdesivir (Fig. 4). Experimental nucleosides and approved nucleoside analogues have been used against SARS-CoV-2 (65). Remdesivir (GS-5734) is a monophosphoramidate analogue of adenosine with potency against Ebola virus (66). The 1'-cyano-substituted adenine ribose analogues have exhibited significant activity against RNA viruses (67). In addition, $C$-nucleosides are more stable than the natural and synthetic $N$-nucleoside congeners, which are vulnerable to enzymatic and acid-catalyzed hydrolysis of the nucleosidic bond (68). GS-5734 has to be anabolized intracellularly to the active triphosphate metabolite, which acts as a chain terminator of viral RNA-dependent RNA-polymerases. The parent nucleoside is modified by a monophosphate prodrug moiety of the 2-ethylbutyl $L$-alaninate and enhances the intracellular triphosphate metabolite concentrations, bypassing the rate-limiting first phosphorylation kinetics (69). 


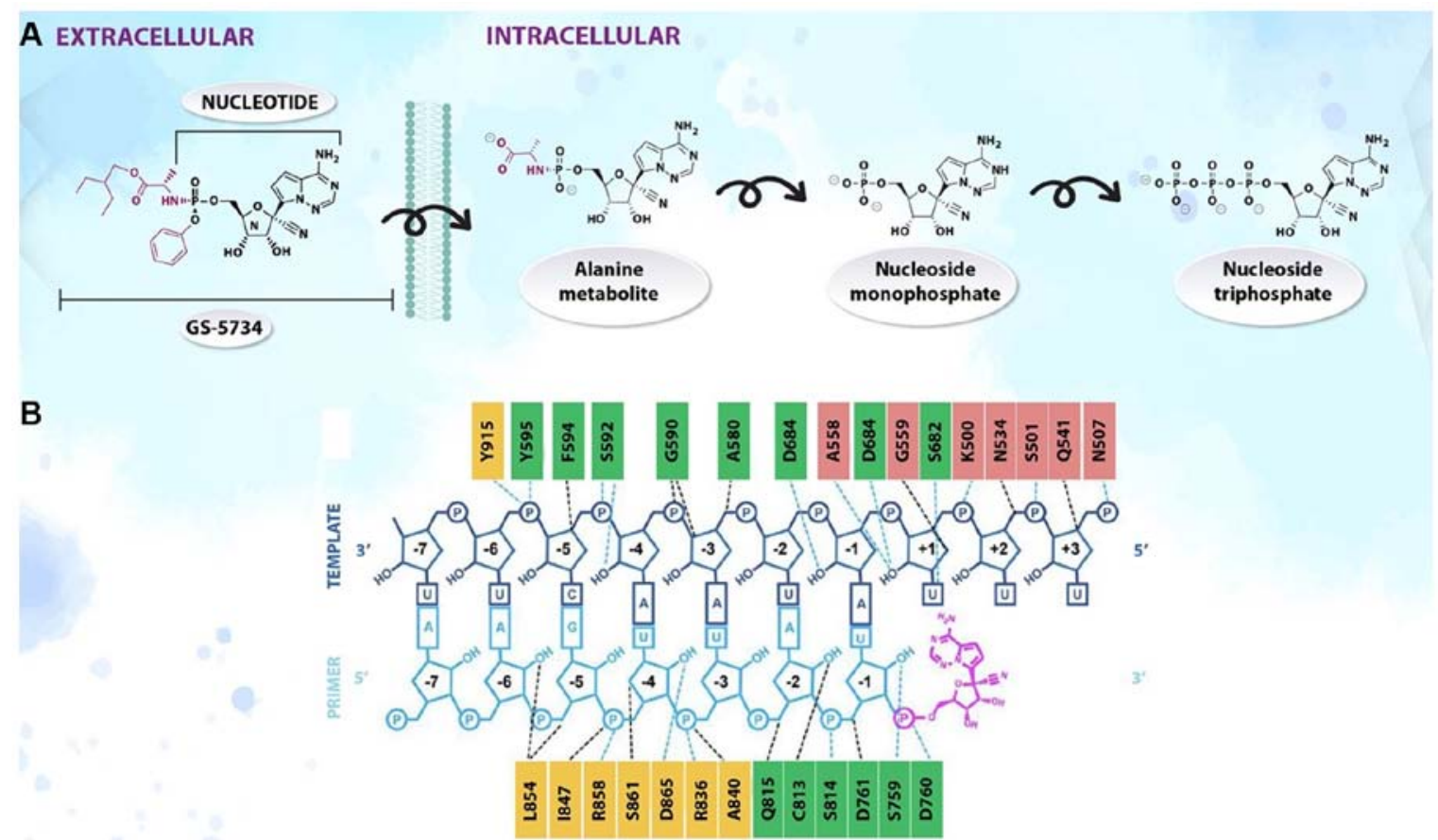

Figure 4. (A) Metabolism and (B) mechanism of action of remdesivir.

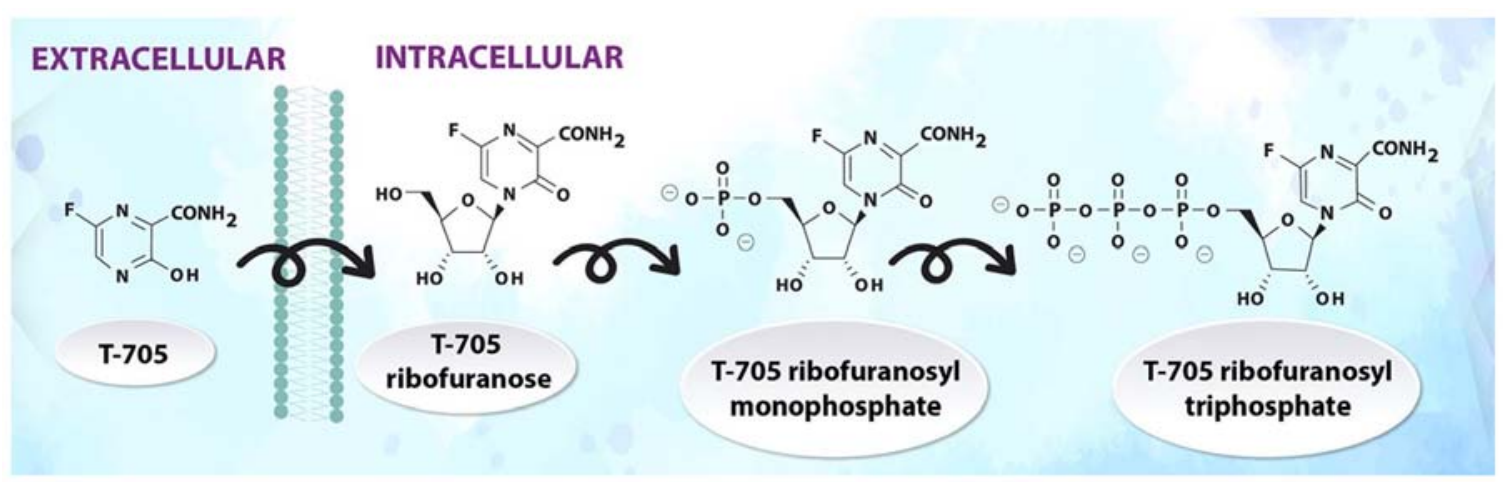

Figure 5. Metabolism of favipiravir.

Remdesivir has a broad-spectrum of antiviral activity against several emerging viral pathogens, including Ebola, Marburg, MERS and SARS. In vitro testing conducted by Gilead Sciences, Inc. demonstrated that remdesivir may be active against the SARS-CoV-2 virus. Currently, the safety and efficacy of remdesivir for the treatment of COVID-19 are being evaluated in numerous ongoing phase III clinical trials (70). However, although several antiviral drugs are being tested against SARS-CoV-2 in vitro, no drugs are currently available with proven effectiveness in patients with severe COVID-19 infection (71).

A cohort study by Grein et al (72) on hospitalized patients with severe COVID-19 who were treated with compassionate use of remdesivir revealed that improvement was observed in $68 \%$ of patients in the respiratory support category (ambient air, non-invasive oxygen support, invasive mechanical ventilation and extracorporeal membrane oxygenation). In another randomized, double-blind, multicenter trial, the Adaptive COVID-19 Treatment Trial (ACTT) (73), the antiviral drug remdesivir was compared with a placebo in hospitalized patients with severe COVID-19 symptoms. At present, ACTT results from patients treated with remdesivir compared with a placebo had a $31 \%$ faster time to recovery (median time to recovery: 11 vs. 15 days). Other clinical trials are under way to assess the safety and efficacy of remdesivir $(74,75)$.

Gilead Sciences, Inc. has initiated two randomized, open-label, multi-center phase III clinical trials for remdesivir, the SIMPLE trials $(74,75)$, in countries with a high prevalence of COVID-19. The first aims to evaluate the safety and efficacy of 5- and 10-day dosing regimens of intravenous remdesivir in hospitalized patients with severe manifestations of COVID-19, and the second in patients with moderate symptoms of COVID-19, compared with standard of care. According to Gilead Sciences, Inc., in an exploratory analysis, 10-day treatment with remdesivir achieved similar improvement in the clinical status of patients compared with a 5-day treatment course (70).

Favipiravir (Fig. 5). Favipiravir (T-705) is a guanine analogue against influenza, which was approved in Japan in 2014. T-705 inhibits the RNA-dependent RNA polymerase 
of RNA viruses, such as influenza, Ebola, yellow fever, chikungunya, norovirus and enterovirus (76), and was recently quite successfully tested against SARS-CoV-2 (65). Favipiravir undergoes intracellular phosphoribosylation to form the active ribofuranosyl triphosphate metabolite $(77,78)$.

Favipiravir has shown encouraging results in Chinese clinical trials; in particular, it accelerated the recovery of hospitalized patients and improved lung function. It has a broad spectrum of activity against RNA viruses, but not against DNA viruses (76). Cai et al (79) compared favipiravir with lopinavir/ritonavir for the treatment of COVID-19 in a non-randomized clinical trial, and revealed that favipiravir had a greater effect on viral clearance and greater improvements on chest computed tomography scans. In addition, Chen et al (80) designed a multi-center randomized superiority clinical trial of favipiravir versus umifenovir for the treatment of patients with COVID-19 in Wuhan, China (77). It was revealed that favipiravir significantly improved pyrexia and cough, but did not significantly improve the clinical recovery rate at day 7 . Currently, this drug is not available in Europe; however, there are ongoing randomized clinical trials (81-84), which aim to evaluate the role of favipiravir in patients with COVID-19; further results are expected after May, 2020.

Ribavirin. Ribavirin is a purine nucleoside analogue that is used to treat numerous viruses, such as respiratory syncytial virus and hepatitis $C(85)$. Ribavirin prevents the replication of viruses by inhibiting the cellular enzyme inosine monophosphate dehydrogenase (86). Additionally, the 5'-triphosphate metabolite of ribavirin inhibits viral polymerase activity.

Although ribavirin has been reported to have little inhibitory effect on coronavirus replication, it decreased the production of proinflammatory cytokines, such as IL-1 and TNF- $\alpha$, in the macrophages of mice (87). Ribavirin exhibits immunomodulatory potency as well as antiviral activity, and has already been used against SARS-CoV and MERS-CoV (85). Ribavirin is being tested in clinical trials against COVID-19 and has shown promising results when used as a triple combination with interferon (IFN) $\beta-1 \mathrm{~b}$ and lopinavir-ritonavir (88).

HIV protease inhibitors: Kaletra (lopinavir/ritonavir). Lopinavir and ritonavir are HIV protease inhibitors (89), which have been specifically designed to fit a certain HIV protease dimer pocket that is not present in coronavirus proteases. The combination of lopinavir/ritonavir was initially thought to be a promising combination against COVID-19, based on its mechanism of action, but ultimately did not prove useful in combating COVID-19. Initially, significant antiviral activity of lopinavir/ritonavir against SARS-CoV was reported in cell cultures; however, there were conflicting results for MERS-CoV (90). A randomized, controlled, open-label trial by Cao et al (91) revealed that the combination of lopinavir/ritonavir in hospitalized adult patients with severe COVID-19 had no benefit compared with the control group. No significant effect was detected on primary outcome and time to clinical improvement (HR, 1.31); in addition, mortality at 28 days was similar in the lopinavir/ritonavir group compared with the standard-care group (19.2 vs. 25.0\%) (91).

Another ongoing multicenter randomized clinical trial (currently in phase II; estimated completion: May, 2020) aims to compare the lopinavir/ritonavir combination with hydroxychloroquine in patients with mild COVID-19, and will investigate whether these treatments reduce the viral load from the respiratory specimens of these patients (32). More randomized clinical trials $(92,93)$ are still ongoing, and the results will soon become available. Recently, the results of a multicenter randomized phase II trial were published, which compared a 14-day triple combination of lopinavir/ritonavir, ribavirin and IFN $\beta-1 b$ with lopinavir-ritonavir alone, for the treatment of hospitalized patients with mild to moderate COVID-19 (94). The results revealed that early triple antiviral combination improved the symptoms of patients compared with lopinavir/ritonavir alone; it also reduced the duration of hospitalization (91). Another possible treatment includes homoharringtonine, which has been reported to be active against herpes viruses, coronaviruses and rhabdoviruses (95). An in vitro study reported that homoharringtonine inhibited SARS-CoV-2 (half maximal effective concentration, $2.10 \mu \mathrm{M}$ ); therefore, it could serve as a potential agent to be used in clinical trials for COVID-19 (96). The combinational therapies of the aforementioned drugs may decrease the effective concentration of the antivirals below therapeutic plasma concentrations and provide better clinical benefits (96).

Targeting proinflammatory hypercytokinemia: Tocilizumab and leronlimab. Increased death rates have been noted in patients with certain risk factors, due to an overwhelming reaction of the immune system to the virus, causing hypercytokinemia (termed cytokine storm), i.e. cytokine-release syndrome (CRS) and macrophage activation syndrome (MAS), which can result in ARDS (97). CRS has been seen in response to coronaviruses, including SARS and MERS, with a high expression of IL-6. Several research reports have demonstrated that some proinflammatory cytokines are increased in the plasma of patients with COVID-19 $(96,97)$. Therefore, it was suggested that cytokine-targeted biological therapies may improve outcomes in CRS or MAS (97).

Therapies that are being investigated for the treatment of patients with COVID-19 with severe respiratory distress, symptom exacerbation and hyperinflammatory syndrome include monoclonal antibodies, such as tocilizumab (IL-6 antagonist), leronlimab (C-C chemokine receptor type 5 inhibitor) and Janus kinase inhibitors $(98,99)$. The CORIMUNO-19 clinical trial platform was designed and developed quickly to evaluate the efficacy and safety of various immune system regulators, as well as other treatments in adult patients with severe COVID-19 infection (100). The primary outcome was the need for ventilation or death at day 14; the results revealed that a significantly lower proportion of patients in the tocilizumab arm reached the primary outcome (101).

IL-6 is a cytokine that is thought to increase even further the inflammation in COVID-19, thus leading to the production of more cytokines, macrophages and cytotoxic lymphocytes that increase lung inflammation. Increased IL- 6 levels have been reported to be related to ARDS (102). Tocilizumab, an anti-IL-6 receptor (IL-6R) biological therapy, has been approved for the treatment of CRS and is also used to treat patients with MAS. A small clinical trial from China exhibited good efficacy in patients with COVID-19 treated with tocilizumab (103). Phase II trials $(104,105)$ have shown that tocilizumab, by blocking IL-6R, may reduce inflammatory markers in patients with COVID-19 and accelerate clinical improvement. 
COVACTA (106) is a phase III randomized clinical trial, which aims to evaluate intravenous tocilizumab combined with standard of care, compared with a placebo plus standard of care in patients with severe COVID-19 pneumonia. Early data from a clinical trial in France has shown encouraging results of tocilizumab in critically ill patients with COVID-19 (107). The National Health Commission of China has also suggested the use of tocilizumab in patients with COVID-19 with extensive bilateral lung lesions opacity or in critically ill patients with increased IL-6 levels (102).

IFN $\lambda s$. IFN $\lambda$ s are crucial for maintaining a balanced antiviral response in the respiratory tract, by inducing viral resistance to cells and helping them deal with the virus load (108). Recombinant or pegylated forms of IFN $\lambda$ can prevent a cytokine storm and reduce viral load, thus preventing lung tissue damage (109). IFN $\lambda$ may be a promising therapy for the treatment of patients with COVID-19, which should be tested in clinical trials, as it may prevent severe pneumonia symptoms and ARDS, and thus death. Lung inflammation and tissue damage are some of the severe signs of COVID-19 infection, which arise due to cytokine storm (110). However, it still needs to be evaluated whether, by stimulating IFN $\lambda$ s or if severe inflammation is present, they can be upregulated and thus increase the possibility of adverse effects on humans (111).

Antiparasitics. Ivermectin, an antiparasitic agent by Merck Sharp \& Dohme, is the generic name given to a mixture of two chemically modified avermectins containing $\geq 80 \%$ 22,23-dihydroavermectin $B_{1 a}$ and $<20 \%$ of the corresponding $B_{1 b}$ homologue. Avermectins are macrolide antibiotics derived from the fermentation products of the actinomycete Streptomyces avermitilis (112). Ivermectin demonstrated in vitro inhibitory action against the replication of SARS-CoV-2 (113). Ivermectin has an established safety profile for human use and has been approved for the treatment of several parasitic infections $(114,115)$. Therefore, it is worthy of further consideration as an antiviral agent against SARS-CoV-2. Furthermore, nitazoxanide, a US Food and Drug Administration-approved drug with a broad spectrum of antiparasitic and antiviral activity, has been suggested to be included in a new protocol for the early management of COVID-19, in combination with azithromycin (116). Nitazoxanide has already been repurposed for the treatment of influenza-like infections and may exhibit a synergistic effect with hydroxychloroquine. In addition, because nitazoxanide upregulates the innate immune response in order to prevent viral replication, it could reduce overall viral load of SARS-CoV2 (117).

\section{Miscellaneous}

Nicotine. Nicotine is a cholinergic agonist and an inhibitor of proinflammatory cytokines (118). Notably, nicotine inhibits TNF, IL-1 and IL-6, which are increased in patients with COVID-19 and are involved in the cytokine storm, leading to rapid deterioration (118). Thus, nicotine, by acting on the cholinergic anti-inflammatory system, has anti-inflammatory properties that may have a protective role in patients with COVID-19, by preventing the cytokine storm. Therefore, nicotine administration could be considered as an add-on therapy, alongside other medications, for the treatment of COVID-19.
However, clinical studies are required in order to confirm this hypothesis.

Vitamin D. Vitamin D deficiency is a major problem worldwide and low serum levels of vitamin D may increase susceptibility to respiratory tract infections. Martineau et al (119) performed a systematic review and reported that vitamin D may protect against acute respiratory tract infections; people with a severe vitamin D deficiency experienced the most benefit from its administration. Vitamin D has been reported to prevent the release of increased inflammatory cytokines by changing the response of macrophages (120). Moreover, it has been demonstrated that infection with COVID-19 may lead to the release of proinflammatory cytokines, thus vitamin D may have a protective role against this (121).

Spironolactone. Recently, there have been some concerns about the use of spironolactone for the treatment of acne in patients with COVID-19 a small study from 2005 reported that macrophages taken from 10 patients with heart failure, who had been on spironolactone daily for a month, had increased ACE2 activity (122). However, spironolactone may have a protective action, as SARS-CoV-2 requires androgens to infect cells (123). In general, the entry of coronaviruses into host cells relies on binding of their viral spike $S$ proteins to cellular receptors, and on $\mathrm{S}$ protein priming by host cell proteases. SARS-CoV-2 uses the receptor ACE2 for entry and the serine protease TMPRSS2 for S protein priming (53). Therefore, spironolactone, being an androgen blocker, may have a protective role against the virus, as well as having some lung and heart benefits (122). The lack of androgens could be a possible explanation for the rare cases of mortality among children with COVID-19, and the high number of male COVID-19-related fatalities in comparison to female fatalities (124). An ongoing randomized clinical trial aims to evaluate the role of spironolactone in COVID-19-induced ARDS (125).

\section{Immunization}

Vaccines. As of May, 2020, there is no approved vaccine against COVID-19, but several are being tested in clinical trials (52). As well as research into vaccines against SARS-CoV-2, there have been some reports that Bacillus Calmette-Guérin (BCG), a vaccine against tuberculosis, may have a protective role against viral infections. Specifically, this vaccine affects the release of proinflammatory cytokines, which have a significant role in fighting viral infections (126). An epidemiological analysis revealed that countries with a BCG vaccination policy, such as Japan, had lower mortality rates compared with Italy, which does not have a BCG vaccination policy (127). BCG vaccination has also been shown to offer protection against viral infections and sepsis, by offering bystander immunity (128); therefore, it might have a positive impact against COVID-19. The BRACE and BADAS randomized trials, which are still recruiting patients, aim to determine whether the $B C G$ vaccine reduces the incidence and severity of COVID-19 $(129,130)$.

It has also been suggested that the Measles Mumps Rubella vaccine may provide a protective role against COVID-19, as it increases the ability of the immune system to fight infection (131). Moreover, there are some structural similarities 
between measles and COVID-19, which may cause cross-reactivity and thus protection against infection (131). However, for both vaccines, randomized clinical trials are essential in order to evaluate their role against SARS-CoV-2. There are currently several potent vaccines against COVID-19, which are being tested, some of which have already entered phase I.

Passive immunization. Current data have suggested that collected IgM and IgG antibodies from patients who have recovered from COVID-19 infection might be a therapeutic option for SARS-CoV-2, as they increase neutralizing antibodies (132). Until vaccines are discovered, passive immunization could be an alternative treatment strategy, particularly for high-risk groups, such as the elderly or patients with cancer (132). Keith et al (133) suggested the use of therapeutic plasma exchange (TPE) as a possible treatment for COVID-19 early in the clinical course, before patients proceed to septic shock or multiple organ failure. Plasma obtained from convalescent donors could be a possible therapeutic option against viral infections, an approach that has also been tried in the past (134). However, Honore et al (135) expressed serious doubts over the use of TPE, as it poses a risk in altering the host immune response. Notably, TPE may aggravate immunoparalysis, as it can remove protective antibodies from the patients and dilute the adaptive response to infection (135). Thus, the safety, efficacy and associated risks of TPE should be tested in randomized clinical trials.

\section{Conclusions}

In conclusion, the treatment regimens used to treat COVID-19, based on recent protocols, consist of known drugs that act against other diseases. The urgent need to treat this deadly pandemic requires the use of known drugs, at least until novel drugs and vaccines with specific/selective action against the virus are discovered. Four randomized trials have already been launched internationally in order to identify effective drugs, the first one for remdesivir (ACTT), the second and third for lopinavir/ritonavir [CATCO (136) and REMAP-CAP (137)] and the fourth for remdesivir and lopinavir/ritonavir, with or without IFN $\beta-1 \alpha$ and hydroxychloroquine [DisCoVeRy (138)]. The European Medicines Agency is in contact with those responsible for the development of twelve possible vaccines against COVID-19, and two vaccines have already been introduced in phase I clinical trials. Vaccine development schedules are difficult to predict, but it is estimated that it will take at least one year for a vaccine to be approved and be available in sufficient quantities in order to be widely used.

\section{Acknowledgements}

The authors would like to thank Ms. Mirto Altani, a graphic designer, for generating Figs. 1, 3, 4 and 5.

\section{Funding}

No funding was received.

\section{Availability of data and materials}

Not applicable.

\section{Authors' contributions}

SK and IPP were involved in data reviewing and writing. SK and IPP have read and approved the final manuscript.

\section{Ethics approval and consent to participate}

Not applicable.

\section{Patient consent for publication}

Not applicable.

\section{Competing interests}

The authors declare that they have no competing interests.

\section{Authors' information}

Miss Sofia Konstantinidou is an Onassis Foundation Scholar.

\section{References}

1. Anastassopoulou C, Russo L, Tsakris A and Siettos C: Data-based analysis, modelling and forecasting of the COVID-19 outbreak. PLoS One 15: e0230405, 2020.

2. Coronaviridae Study Group of the International Committee on Taxonomy of Viruses: The species Severe acute respiratory syndrome-related coronavirus: Classifying 2019-nCoV and naming it SARS-CoV-2. Nat Microbiol 5: 536-544, 2020.

3. Almeida JD and Tyrrell DAJ: The morphology of three previously uncharacterized human respiratory viruses that grow in organ culture. J Gen Virol 1: 175-178, 1967.

4. Docea AO, Tsatsakis A, Albulescu D, Cristea O, Zlatian O, Vinceti M, Moschos SA, Tsoukalas D, Goumenou M, Drakoulis N, et al: A new threat from an old enemy: Re emergence of coronavirus (Review). Int J Mol Med 45: 1631-1643, 2020.

5. Ye ZW, Yuan S, Yuen KS, Fung SY, Chan CP and Jin DY: Zoonotic origins of human coronaviruses. Int J Biol Sci 16: 1686-1697, 2020.

6. Ksiazek TG, Erdman D, Goldsmith CS, Zaki SR, Peret T, Emery S, Tong S, Urbani C, Comer JA, Lim W, et al; SARS Working Group: A novel coronavirus associated with severe acute respiratory syndrome. N Engl J Med 348: 1953-1966, 2003.

7. Fehr AR, Channappanavar R and Perlman S: Middle East respiratory syndrome (MERS): Emergence of a pathogenic human Coronavirus. Annu Rev Med 68: 387-399, 2017.

8. Lu R, Zhao X, Li J, Niu P, Yang B, Wu H, Wang W, Song H, Huang B, Zhu N, et al: Genomic characterisation and epidemiology of 2019 novel coronavirus: Implications for virus origins and receptor binding. Lancet 395: 565-574, 2020.

9. Gates B: Responding to Covid-19 - A Once-in-a-Century Pandemic? N Engl J Med 382: 1677-1679, 2020.

10. Gates B: Innovation for Pandemics. N Engl J Med 378: 2057-2060, 2018.

11. Wu G, Zhao T, Kang D, Zhang J, Song Y, Namasivayam V, Kongsted J, Pannecouque C, De Clercq E, Poongavanam V, et al: Overview of recent strategic advances in medicinal chemistry. $\mathrm{J}$ Med Chem 62: 9375-9414, 2019.

12. Touret $\mathrm{F}$ and de Lamballerie $\mathrm{X}$ : Of chloroquine and COVID-19. Antiviral Res 177: 104762, 2020.

13. Cortegiani A, Ingoglia G, Ippolito M, Giarratano A and Einav S: A systematic review on the efficacy and safety of chloroquine for the treatment of COVID-19. J Crit Care 57: 279-283, 2020.

14. Colson P, Rolain JM, Lagier JC, Brouqui P and Raoult D: Chloroquine and hydroxychloroquine as available weapons to fight COVID-19. Int J Antimicrob Agents 55: 105932, 2020.

15. Ben-Zvi I, Kivity S, Langevitz $\mathrm{P}$ and Shoenfeld Y: Hydroxychloroquine: From malaria to autoimmunity. Clin Rev Allergy Immunol 42: 145-153, 2012.

16. Witiak DT, Grattan DA, Heaslip RJ and Rahwan RG: Synthesis and preliminary pharmacological evaluation of asymmetric chloroquine analogues. J Med Chem 24: 712-717, 1981.

17. Chloroquine - an overview I ScienceDirect Topics. Sci Direct. 
18. Circu M, Cardelli J, Barr MP, O'Byrne K, Mills G and El-Osta H: Modulating lysosomal function through lysosome membrane permeabilization or autophagy suppression restores sensitivity to cisplatin in refractory non-small-cell lung cancer cells. PLoS One 12: e0184922, 2017.

19. Schrezenmeier E and Dörner T: Mechanisms of action of hydroxychloroquine and chloroquine: Implications for rheumatology. Nat Rev Rheumatol 16: 155-166, 2020.

20. van den Borne BEEM, Dijkmans BAC, de Rooij HH, le Cessie S and Verweij CL: Chloroquine and hydroxychloroquine equally affect tumor necrosis factor- $\alpha$, interleukin 6 , and interferon- $\gamma$ production by peripheral blood mononuclear cells. J Rheumatol 24: 55-60, 1997.

21. Gordon DE, Jang GM, Bouhaddou M, Xu J, Obernier K White KM, O'Meara MJ, Rezelj VV, Guo JZ, Swaney DL, et al: A SARS-CoV-2 protein interaction map reveals targets for drug repurposing. Nature: Apr 30, 2020 (Epub ahead of print). doi: $10.1038 / \mathrm{s} 41586-020-2286-9$

22. Encinar JA and Menendez JA: Potential drugs targeting early innate immune evasion of SARS-coronavirus 2 via 2'-O-methylation of viral RNA. Viruses 12: E525,2020.

23. Keyaerts E, Vijgen L, Maes P, Neyts J and Van Ranst M: In vitro inhibition of severe acute respiratory syndrome coronavirus by chloroquine. Biochem Biophys Res Commun 323: 264-268, 2004.

24. Wang M, Cao R, Zhang L, Yang X, Liu J, Xu M, Shi Z, Hu Z, Zhong W and Xiao G: Remdesivir and chloroquine effectively inhibit the recently emerged novel coronavirus $(2019-\mathrm{nCoV})$ in vitro. Cell Res 30: 269-271, 2020.

25. Liu J, Cao R, Xu M, Wang X, Zhang H, Hu H, Li Y, Hu Z, Zhong W and Wang M: Hydroxychloroquine, a less toxic derivative of chloroquine, is effective in inhibiting SARS-CoV-2 infection in vitro. Cell Discov 6: 16, 2020.

26. Hache Guillaume RJMGP, DJBPRDHS Hydroxychloroquine-Azithromycin and COVID-19 - IHU, 2020

27. Rosenberg ES, Dufort EM, Udo T, Wilberschied LA, Kumar J, Tesoriero J, Weinberg P, Kirkwood J, Muse A, DeHovitz J, et al: Association of treatment with hydroxychloroquine or azithromycin with in-Hospital Mortality in patients with COVID-19 in New York State. JAMA: May 11, 2020 (Epub ahead of print). doi: 10.1001/jama.2020.8630.

28. Doudier B and Courjon J: Hydroxychloroquine and azithromycin as a treatment of COVID-19, 2020.

29. Gao J, Tian Z and Yang X: Breakthrough: Chloroquine phosphate has shown apparent efficacy in treatment of COVID-19 associated pneumonia in clinical studies. Biosci Trends 14: 72-73, 2020.

30. Zhao M: Cytokine storm and immunomodulatory therapy in COVID-19: Role of chloroquine and anti-IL-6 monoclonal antibodies. Int J Antimicrob Agents 55: 105982, 2020.

31. Efficacy and safety of hydroxychloroquine for treatment of COVID-19. ClinicalTrials.gov.

32. Comparison of lopinavir/ritonavir or hydroxychloroquine in patients with mild coronavirus disease (COVID-19). ClinicalTrials gov. https://clinicaltrials.gov/ct2/show/NCT04307693. Accessed March 13, 2020

33. Yao X, Ye F, Zhang M, Cui C, Huang B, Niu P, Liu X, Zhao L, Dong E, Song $\mathrm{C}$, et al: In vitro antiviral activity and projection of optimized dosing design of hydroxychloroquine for the treatment of severe acute respiratory syndrome coronavirus 2 (SARS-CoV-2). Clin Infect Dis: Mar 9, 2020 (Epub ahead of print). doi: 10.1093/cid/ciaa237.

34. The PATCH Trial (prevention and treatment of COVID-19 with hydroxychloroquine). ClinicalTrials.gov. https://clinicaltrials gov/ct2/show/NCT04329923. Accessed April 1, 2020.

35. Karalis V, Ismailos G and Karatza E: Chloroquine dosage regimens in patients with COVID-19: safety risks and optimization using simulations. Saf Sci 129: 104842. 2020

36. Lane JC, Weaver J, Kostka K, Duarte-Salles T, Abrahao MT, Alghoul H, Alser O, Alshammari TM, Biedermann P, Burn E, et al: Safety of hydroxychloroquine, alone and in combination with azithromycin, in light of rapid wide-spread use for COVID-19: a multinational, network cohort and self-controlled case series study. medRxiv: May 31, 2020 (Epub ahead of print). doi: org/10.1101/2020.04.08.20054551.

37. Al-Bari MA: Chloroquine analogues in drug discovery: New directions of uses, mechanisms of actions and toxic manifestations from malaria to multifarious diseases. J Antimicrob Chemother 70: 1608-1621, 2015.

38. Mehra MR, Desai SS, Ruschitzka F and Patel AN: Articles Hydroxychloroquine or chloroquine with or without a macrolide for treatment of COVID-19: A multinational registry analysis. Lancet 6736: 1-10, 2020.
39. Karalis V, Ismailos $\mathrm{G}$ and Karatza E: Chloroquine dosage regimens in patients with COVID-19: Safety risks and optimization using simulations. Saf Sci 129: 104842, 2020.

40. Driggin E, Madhavan MV, Bikdeli B, Chuich T, Laracy J, Biondi-Zoccai G, Brown TS, Der Nigoghossian C, Zidar DA, Haythe J, et al: Cardiovascular considerations for patients, health care workers, and health systems during the COVID-19 pandemic. J Am Coll Cardiol 75: 2352-2371, 2020.

41. Deftereos SG, Siasos G, Giannopoulos G, Vrachatis DA, Angelidis C, Giotaki SG, Gargalianos P, Giamarellou H, Gogos C, Daikos G, et al: The Greek study in the effects of colchicine in COvid-19 complications prevention (GRECCO-19 study): Rationale and study design. Hellenic J Cardiol: Apr 3, 2020 (Epub ahead of print). doi: 10.1016/j.hjc.2020.03.002.

42. Colchicine Coronavirus SARS-CoV2 Trial (COLCORONA) ClinicalTrials.gov. https://clinicaltrials.gov/ct2/show/ NCT04322682. Accessed March 26, 2020.

43. Walls AC, Park YJ, Tortorici MA, Wall A, McGuire AT and Veesler D: Structure, function, and antigenicity of the SARS-CoV-2 spike glycoprotein. Cell 181: 281-292.e6, 2020.

44. Morse JS, Lalonde T, Xu S and Liu WR: Learning from the past: Possible urgent prevention and treatment options for severe acute respiratory infections caused by $2019-\mathrm{nCoV}$. ChemBioChem 21: 730-738, 2020.

45. Li F: Receptor recognition and cross-species infections of SARS coronavirus. Antiviral Res 100: 246-254, 2013.

46. Ocaranza MP, Michea L, Chiong M, Lagos CF, Lavandero S and Jalil JE: Recent insights and therapeutic perspectives of angiotensin-(1-9) in the cardiovascular system. Clin Sci (Lond) 127: 549-557, 2014.

47. Li SR, Tang ZJ, Li ZH and Liu X: Searching therapeutic strategy of new coronavirus pneumonia from angiotensin-converting enzyme 2: the target of COVID-19 and SARS-CoV. Eur J Clin Microbiol Infect Dis 39: 1021-1026, 2020.

48. Yan T, Xiao R and Lin G: Angiotensin-converting enzyme 2 in severe acute respiratory syndrome coronavirus and SARS-CoV-2: A double-edged sword? FASEB J 34: 6017-6026, 2020.

49. Imai Y, Kuba K and Penninger JM: The discovery of angiotensin-converting enzyme 2 and its role in acute lung injury in mice. Exp Physiol 93: 543-548, 2008.

50. Rothlin RP, Vetulli HM, Duarte $M$ and Pelorosso FG: Telmisartan as tentative angiotensin receptor blocker therapeutic for COVID-19. Drug Dev Res: May 1, 2020 (Epub ahead of print). doi: 10.1002/ddr.21679.

51. Zhang H, Penninger JM, Li Y, Zhong N and Slutsky AS: Angiotensin-converting enzyme 2 (ACE2) as a SARS-CoV-2 receptor: Molecular mechanisms and potential therapeutic target. Intensive Care Med 46: 586-590, 2020.

52. Thanh Le T, Andreadakis Z, Kumar A, Gómez Román R, Tollefsen S, Saville M and Mayhew S: The COVID-19 vaccine development landscape. Nat Rev Drug Discov 19: 305-306, 2020.

53. Hoffmann M, Kleine-Weber H, Schroeder S, Krüger N, Herrler T, Erichsen S, Schiergens TS, Herrler G, Wu NH, Nitsche A, et al: SARS-CoV-2 cell entry depends on ACE2 and TMPRSS2 and is blocked by a clinically proven protease inhibitor. Cell 181: 271-280.e8, 2020.

54. Iwata-Yoshikawa N, Okamura T, Shimizu Y, Hasegawa H, Takeda M and Nagata N: TMPRSS2 contributes to virus spread and immunopathology in the airways of murine models after coronavirus infection. J Virol 93: 93, 2019.

55. Verdecchia P, Cavallini C, Spanevello A and Angeli F: The pivotal link between ACE2 deficiency and SARS-CoV-2 infection. Eur J Intern Med 76: 14-20, 2020.

56. Saavedra JM: Angiotensin receptor blockers and COVID-19. Pharmacol Res 156: 104832,2020.

57. Fang L, Karakiulakis G and Roth M: Are patients with hypertension and diabetes mellitus at increased risk for COVID-19 infection? Lancet Respir Med 8: e21, 2020.

58. Diaz JH: Hypothesis: angiotensin-converting enzyme inhibitors and angiotensin receptor blockers may increase the risk of severe COVID-19 Running Title: Angiotensin Receptor and COVID-19. J Travel Med 27: taaa041, 2020.

59. Gurwitz D: Angiotensin receptor blockers as tentative SARS-CoV-2 therapeutics. Drug Dev Res 1: 4, 2020.

60. Zhang P, Zhu L, Cai J, Lei F, Qin JJ, Xie J, Liu YM, Zhao YC, Huang X, Lin L, et al: Association of inpatient use of angiotensin converting enzyme inhibitors and angiotensin II receptor blockers with mortality among patients with hypertension hospitalized with COVID-19. Circ Res 126: 1671-1681, 2020. 
61. Castiglione V, Chiriacò $M$, Emdin $M$, Taddei $S$ and Vergaro G: Statin therapy in COVID-19 infection. Eur Heart J Cardiovasc Pharmacother: Apr 29, 2020 (Epub ahead of print). doi: 10.1093/ehjcvp/pvaa042.

62. Pertzov B, Eliakim-Raz N, Atamna H, Trestioreanu AZ, Yahav D and Leibovici L: Hydroxymethylglutaryl-CoA reductase inhibitors (statins) for the treatment of sepsis in adults - A systematic review and meta-analysis. Clin Microbiol Infect 25: 280-289, 2019.

63. Fedson DS, Opal SM and Rordam OM: Hiding in plain sight: An approach to treating patients with severe covid-19 infection. mBio 11: e00398-20, 2020.

64. Journal EH, Pharmacotherapy C and East M: OUP accepted manuscript. Eur Hear J Cardiovasc Pharmacother, 2020.

65. Li G and De Clercq E: Therapeutic options for the 2019 novel coronavirus (2019-nCoV). Nat Rev Drug Discov 19: 149-150, 2020.

66. Warren TK, Jordan R, Lo MK, Ray AS, Mackman RL, Soloveva V, Siegel D, Perron M, Bannister R, Hui HC, et al: Therapeutic efficacy of the small molecule GS-5734 against Ebola virus in rhesus monkeys. Nature 531: 381-385, 2016.

67. Cho A, Saunders OL, Butler T, Zhang L, Xu J, Vela JE, Feng JY, Ray AS and Kim CU: Synthesis and antiviral activity of a series of 1'-substituted 4-aza-7,9-dideazaadenosine C-nucleosides. Bioorg Med Chem Lett 22: 2705-2707, 2012

68. Stambaský J, Hocek M and Kocovský P: C-nucleosides: Synthetic strategies and biological applications. Chem Rev 109: 6729-6764, 2009.

69. Eastman RT, Roth JS, Brimacombe KR, Simeonov A, Shen M, Patnaik $S$ and Hall MD: Remdesivir: A review of its discovery and development leading to emergency use authorization for treatment of COVID-19. ACS Cent Sci 6: 672-683, 2020.

70. Gilead announces results from phase 3 trial of investigational antiviral remdesivir in patients with severe COVID-19. Gilead Sciences, Inc., 2020

71. Wang Y, Zhang D, Du G, Du R, Zhao J, Jin Y, Fu S, Gao L, Cheng Z, Lu Q, et al: Remdesivir in adults with severe COVID-19: A randomised, double-blind, placebo-controlled, multicentre trial. Lancet 395: 1569-1578, 2020.

72. Grein J, Ohmagari N, Shin D, Diaz G, Asperges E, Castagna A Feldt T, Green G, Green ML, Lescure FX, et al: Compassionate Use of Remdesivir for Patients with Severe Covid-19. N Engl J Med 382: 2327-2336, 2020

73. Adaptive COVID-19 Treatment Trial (ACTT). ClinicalTrials. gov. https://clinicaltrials.gov/ct2/show/NCT04280705. Accessed February 21, 2020

74. Study to evaluate the safety and antiviral activity of remdesivir (GS-5734TM) in participants with moderate coronavirus disease (COVID-19) compared to standard of care treatment. ClinicalTrials.gov. https://clinicaltrials.gov/ct2/show/ NCT04292730. Accessed March 3, 2020.

75. Study to Evaluate the safety and antiviral activity of remdesivir (GS-5734TM) in participants with severe coronavirus disease (COVID-19). ClinicalTrials.gov. https://clinicaltrials.gov/ct2/ show/NCT04292899. Accessed March 3, 2020.

76. Furuta Y, Komeno T and Nakamura T: Favipiravir (T-705), a broad spectrum inhibitor of viral RNA polymerase. Proc Jpn Acad, Ser B, Phys Biol Sci 93: 449-463, 2017.

77. Furuta Y, Takahashi K, Kuno-Maekawa M, Sangawa H, Uehara S, Kozaki K, Nomura N, Egawa H and Shiraki K: Mechanism of action of T-705 against influenza virus. Antimicrob Agents Chemother 49: 981-986, 2005.

78. Smee DF, Hurst BL, Egawa H, Takahashi K, Kadota T and Furuta Y: Intracellular metabolism of favipiravir (T-705) in uninfected and influenza A (H5N1) virus-infected cells. J Antimicrob Chemother 64: 741-746, 2009.

79. Cai Q, Yang M, Liu D, Chen J, Shu D, Xia J, Liao X, Gu Y, Cai Q, Yang Y, et al: Experimental treatment with favipiravir for COVID-19: An open-label control study. Engineering (Beijing): Mar 18,2020 (Epubahead of print). doi: 10.1016/j.eng.2020.03.007.

80. Chen C, Huang J, Cheng Z, Wu J, Chen S, Yongxi Zhang Y, Chen B, Lu M, Luo Y, Zhang J, et al: Favipiravir versus Arbidol for COVID-19: A Randomized Clinical Trial. medRxiv: April 15, 2020 (Epub ahead or ptin). doi.org/10.1101/2020.03.17.20037432.

81. Clinical study to evaluate the performance and safety of favipiravir in COVID-19. ClinicalTrials.gov.

82. Efficacy and safety of favipiravir in management of COVID-19. ClinicalTrials.gov. https://clinicaltrials.gov/ct2/show/ NCT04349241. Accessed April 16, 2020.

83. Clinical trial of favipiravir tablets combine with chloroquine phosphate in the treatment of novel coronavirus pneumonia. ClinicalTrials.gov. https://clinicaltrials.gov/ct $2 /$ show/ NCT04319900. Accessed March 24, 2020.
84. Favipiravir combined with tocilizumab in the treatment of corona virus disease 2019. ClinicalTrials.gov.

85. Cinatl J Jr, Michaelis M, Hoever G, Preiser W and Doerr HW: Development of antiviral therapy for severe acute respiratory syndrome. Antiviral Res 66: 81-97, 2005.

86.Leyssen P, Balzarini J, De Clercq E and Neyts J: The predominant mechanism by which ribavirin exerts its antiviral activity in vitro against flaviviruses and paramyxoviruses is mediated by inhibition of IMP dehydrogenase. J Virol 79: 1943-1947, 2005.

87. Ning Q, Brown D, Parodo J, Cattral M, Gorczynski R, Cole E, Fung L, Ding JW, Liu MF, Rotstein O, et al: Ribavirin inhibits viral-induced macrophage production of TNF, IL-1, the procoagulant fgl 2 prothrombinase and preserves Th1 cytokine production but inhibits Th2 cytokine response. J Immunol 160 3487-3493, 1998

88. Sheahan TP, Sims AC, Leist SR, Schäfer A, Won J, Brown AJ, Montgomery SA, Hogg A, Babusis D, Clarke MO, et al: Comparative therapeutic efficacy of remdesivir and combination lopinavir, ritonavir, and interferon beta against MERS-CoV. Nat Commun 11: 222, 2020.

89. Agbowuro AA, Huston WM, Gamble AB and Tyndall JD Proteases and protease inhibitors in infectious diseases. Med Res Rev 38: 1295-1331, 2018.

90. Delang L and Neyts J: Medical treatment options for COVID-19. Eur Heart J Acute Cardiovasc Care 9: 209-214, 2020.

91. Cao B, Wang Y, Wen D, Liu W, Wang J, Fan G, Ruan L, Song B, Cai Y, Wei M, et al: A Trial of Lopinavir-Ritonavir in Adults Hospitalized with Severe Covid-19. N Engl J Med 382: 1787-1799, 2020.

92. The efficacy of lopinavir plus ritonavir and arbidol against novel coronavirus infection. ClinicalTrials.gov. https://clinicaltrials gov/ct2/show/NCT04252885. Accessed February 5, 2020.

93. Lopinavir/ritonavir, ribavirin and IFN-beta combination for nCoV treatment. ClinicalTrials.gov. https://clinicaltrials.gov/ct2/ show/NCT04276688. Accessed February 19, 2020.

94. Hung IF, Lung KC, Tso EY, Liu R, Chung TW, Chu MY, Ng YY, Lo J, Chan J, Tam AR, et al: Triple combination of interferon beta-1b, lopinavir-ritonavir, and ribavirin in the treatment of patients admitted to hospital with COVID-19: An open-label, randomised, phase 2 trial. Lancet 395: 1695-1704, 2020.

95. Andersen PI, Krpina K, Ianevski A, Shtaida N, Jo E, Yang J, Koit S, Tenson T, Hukkanen V, Anthonsen MW, et al: Novel antiviral activities of obatoclax, emetine, niclosamide, brequinar, and homoharringtonine. Viruses 11: 1-15, 2019.

96. Choy KT, Wong AY, Kaewpreedee P, Sia SF, Chen D, Hui KP, Chu DK, Chan MC, Cheung PP, Huang X, et al: Remdesivir, lopinavir, emetine, and homoharringtonine inhibit SARS-CoV-2 replication in vitro. Antiviral Res 178: 104786, 2020.

97. Zhang C, Wu Z, Li JW, Zhao HW and Wang GQ: The cytokine release syndrome (CRS) of severe COVID-19 and interleukin-6 receptor (IL-6R) antagonist Tocilizumab may be the key to reduce the mortality. Int J Antimicrob Agents 11: 1-6, 2020.

98. Hennon TR, Penque MD, Abdul-Aziz R, Alibrahim OS, McGreevy MB, Prout AJ, Schaefer BA, Ambrusko SJ, Pastore JV, Turkovich SJ, et al: COVID-19 associated multisystem inflammatory syndrome in children (MIS-C) guidelines; a Western New York approach. Prog Pediatr Cardiol 21: 101232, 2020.

99. Huang C, Wang Y, Li X, Ren L, Zhao J, Hu Y, Zhang L, Fan G, $\mathrm{Xu} J, \mathrm{Gu} X$, et al: Clinical features of patients infected with 2019 novel coronavirus in Wuhan, China. Lancet 395: 497-506, 2020.

100. Vijayvargiya P, Garrigos ZE, Almeida NE, Gurram PR, Stevens RW and Razonable RR: In reply-The 'Perfect Cytokine Storm' of COVID-19. Mayo Clin Proc: May 29, 2020 (Epub ahead of print). doi: 10.1016/j.mayocp.2020.05.016.

101. CORIMUNO-19-TocilizumabTrial-TOCI(CORIMUNO-TOCI) ClinicalTrials.gov. https://www.clinicaltrials.gov/ct2/show/ NCT04331808. Accessed April 2, 2020.

102. Fu B, Xu X and Wei H: Why tocilizumab could be an effective treatment for severe COVID-19? J Transl Med 18: 164, 2020.

103.Zhang Q, Wang Y, Qi C, Shen L and Li J: Response to 'Comments on Zhang et al: Clinical trial analysis of 2019-nCoV therapy registered in China'. J Med Virol 92: 713, 2020.

104. Tocilizumab treatmentin patients with COVID-19. ClinicalTrials. gov. https://clinicaltrials.gov/ct2/show/NCT04363853. Accessed April 27, 2020.

105. Tocilizumab in the treatment of coronavirus induced disease (COVID-19). ClinicalTrials.gov. https://www.clinicaltrials.gov/ ct2/show/NCT04335071. Accessed April 6, 2020. 
106. A study to evaluate the safety and efficacy of tocilizumab in patients with severe COVID-19 pneumonia. ClinicalTrials.gov. https://clinicaltrials.gov/ct2/show/NCT04320615. Accessed March 25, 2020.

107. Genentech's arthritis drug tocilizumab shows promise in Covid-19 trial. ClinicalTrials Arena, 2020. https://www.clinicaltrialsarena. com/uncategorized/genentechs-arthritis-drug-tocilizumab-showspromise-in-covid-19-trial/. Accessed April 29, 2020.

108. Andreakos E and Tsiodras S: COVID-19: Lambda interferon against viral load and hyperinflammation. EMBO Mol Med 12: e12465, 2020

109.Davidson S, McCabe TM, Crotta S, Gad HH, Hessel EM, Beinke S, Hartmann R and Wack A: IFN $\lambda$ is a potent anti-influenza therapeutic without the inflammatory side effects of IFN $\alpha$ treatment. EMBO Mol Med 8: 1099-1112, 2016.

110. Mehta P, McAuley DF, Brown M, Sanchez E, Tattersall RS and Manson JJ; HLH Across Speciality Collaboration, UK COVID-19: Consider cytokine storm syndromes and immunosuppression. Lancet 395: 1033-1034, 2020.

111. Prokunina-Olsson L, Alphonse N, Dickenson RE, Durbin JE, Glenn JS, Hartmann R, Kotenko SV, Lazear HM, O'Brien TR, Odendall C, et al: COVID-19 and emerging viral infections: The case for interferon lambda. J Exp Med 217: 5-8, 2020.

112. Bray M, Rayner C and Noël F, Jans D and Wagstaff K Ivermectin and COVID-19: A report in Antiviral Research, widespread interest, an FDA warning, two letters to the editor and the authors' responses. Antiviral Res 178: 104805, 2020.

113. Caly L, Druce JD, Catton MG, Jans DA and Wagstaff KM: The FDA-approved drug ivermectin inhibits the replication of SARS-CoV-2 in vitro. Antiviral Res 178: 104787, 2020.

114. González Canga A, Sahagún Prieto AM, Diez Liébana MJ, Fernández Martínez N, Sierra Vega M and García Vieitez JJ The pharmacokinetics and interactions of ivermectin in humans - a mini-review. AAPS J 10: 42-46, 2008.

115. Buonfrate D, Salas-Coronas J, Muñoz J, Maruri BT, Rodari P, Castelli F, Zammarchi L, Bianchi L, Gobbi F, Cabezas-Fernández T, et al: Multiple-dose versus single-dose ivermectin for Strongyloides stercoralis infection (Strong Treat 1 to 4): A multicentre, open-label, phase 3, randomised controlled superiority trial. Lancet Infect Dis 19: 1181-1190, 2019.

116. Kelleni MT: Nitazoxanide/azithromycin combination for COVID-19: A suggested new protocol for early management Pharmacol Res 157: 104874, 2020.

117.Padmanabhan S: Potential dual therapeutic approach against SARS-CoV-2/COVID-19 with nitazoxanide and hydroxychloroquine. Preprint, 2020.

118. Ulloa L: The vagus nerve and the nicotinic anti-inflammatory pathway. Nat Rev Drug Discov 4: 673-684, 2005.

119. Martineau AR, Jolliffe DA, Hooper RL, Greenberg L, Aloia JF, Bergman P, Dubnov-Raz G, Esposito S, Ganmaa D, Ginde AA, et al: Vitamin D supplementation to prevent acute respiratory tract infections: Systematic review and meta-analysis of individual participant data. BMJ 356: i6583, 2017.

120.Helming L, Böse J, Ehrchen J, Schiebe S, Frahm T, Geffers R, Probst-Kepper M, Balling R and Lengeling A: $1 \alpha, 25$-Dihydroxyvitamin D3 is a potent suppressor of interferon $\gamma$-mediated macrophage activation. Blood 106: 4351-4358, 2005.

121. Ilie PC, Stefanescu S and Smith L: The role of Vitamin D in the prevention of Coronavirus Disease 2019 infection and mortality. Aging Clin Exp Res: May 6, 2020 (Epub ahead of print). doi: 10.1007/s40520-020-01570-8.

122. Alexander OM: Evidence on spironolactone safety in COVID-19 reassuring. Medscape: April 29, 2020 (Epub ahead of print).
123. Gustavo Carlos Wambier GA: Severe acute respiratory syndrome coronavirus 2 (SARS-CoV-2) infection is likely to be androgen mediated. J Am Acad Dermatol 21: 1-9, 2020.

124. Jin JM, Bai P, He W, Wu F, Liu XF, Han DM, Liu S and Yang JK: Gender differences in patients with COVID-19: Focus on severity and mortality. Front Public Health 8: 152, 2020.

125. Spironolactone in Covid-19 Induced ARDS. ClinicalTrials.gov. https://www.smartpatients.com/trials/NCT04345887. Accessed April, 2020

126.Kleinnijenhuis J, Quintin J, Preijers F, Benn CS, Joosten LA, Jacobs C, van Loenhout J, Xavier RJ, Aaby P, van der Meer JW, et al: Long-lasting effects of BCG vaccination on both heterologous Th1/Th17 responses and innate trained immunity. J Innate Immun 6: 152-158, 2014.

127. Gearoid R: Japan was expecting a coronavirus explosion. Where is it? The Japan Times, 2020.

128. Moorlag SJ, Arts RJ, van Crevel R and Netea MG: Non-specific effects of BCG vaccine on viral infections. Clin Microbiol Infect 25: 1473-1478, 2019

129. BCG Vaccination to Protect Healthcare Workers Against COVID-19. ClinicalTrials.gov. https://clinicaltrials.gov/ct2/ show/NCT04327206. Accessed March 31, 2020.

130. BCG vaccine for health care workers as defense against COVID-19. ClinicalTrials.gov. https://clinicaltrials.gov/ct2/ show/NCT04348370. Accessed April 16, 2020.

131. Saad M and Elsalamony R: Measles vaccines may provide partial protection against COVID-19. Int J Cancer Biomed Res 5: 14-19, 2020.

132. Fischer JC, Zänker K, van Griensven M, Schneider M, Kindgen-Milles D, Knoefel WT, Lichtenberg A, Tamaskovics B, Djiepmo-Njanang FJ, Budach W, et al: The role of passive immunization in the age of SARS-CoV-2: An update. Eur J Med Res 25: 16, 2020.

133. Keith P, Day M, Perkins L, Moyer L, Hewitt K and Wells A: A novel treatment approach to the novel coronavirus: An argument for the use of therapeutic plasma exchange for fulminant COVID-19. Crit Care 24: 128, 2020.

134. Lennart H, Hassan A and Fausto B, Harold $M$ and Hammarström QP: Development of passive immunity against SARS-CoV-1 2 for management of immunodeficient patients - a perspective. J Allergy Clin Immunol: May 12, 2020 (Epub ahead of print). doi: 10.1016/j.jaci.2020.04.043.

135. Honore PM, Mugisha A, Kugener L, Redant S, Attou R, Gallerani A and De Bels D: Therapeutic plasma exchange as a routine therapy in septic shock and as an experimental treatment for COVID-19: We are not sure. Crit Care 24: 226, 2020.

136. Treatments for COVID-19: Canadian Arm of the SOLIDARITY Trial. ClinicalTrials.gov. https://clinicaltrials.gov/ct2/show/ NCT04330690. Accessed April 1, 2020.

137. Randomized, embedded, multifactorial adaptive platform trial for community- acquired pneumonia. ClinicalTrials.gov. https:// clinicaltrials.gov/ct2/show/NCT02735707. Accessed April 13, 2016.

138. Trial of treatments for COVID-19 in hospitalized adults. ClinicalTrials.gov. https://www.centerwatch.com/clinical-trials/ listings/241173/corona-virus-infection-trial-treatments-covid-19hospitalized/?\&radius=50. Accessed June 2020 .

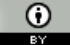

This work is licensed under a Creative Commons Attribution 4.0 International (CC BY 4.0) License. 